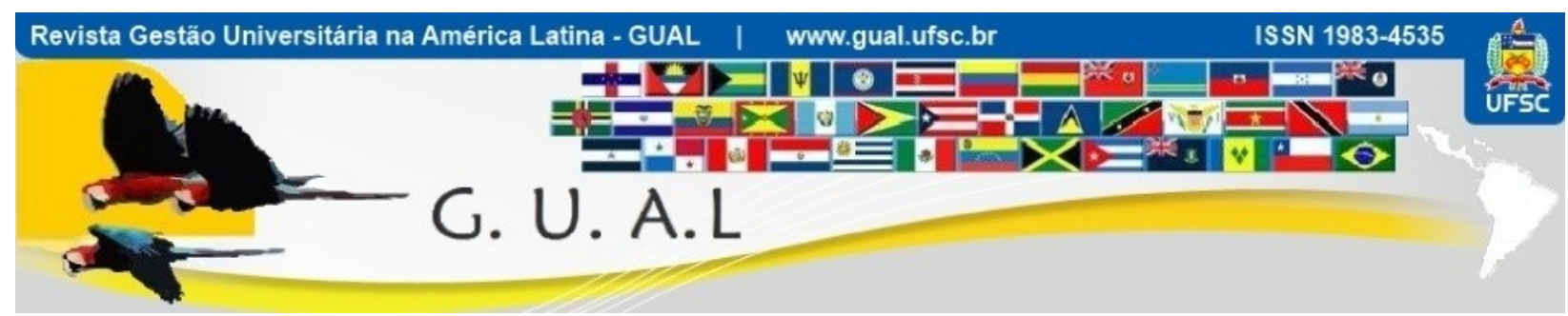

DOI: https://doi.org/10.5007/1983-4535.2021.e74480

\title{
EXIGÊNCIAS PARA AS COMPRAS GOVERNAMENTAIS DAS UNIVERSIDADES FEDERAIS BRASILEIRAS: ANÁLISE DE CONTEÚDO DE ACÓRDÃOS DO TRIBUNAL DE CONTAS DA UNIÃO
}

\section{REQUIREMENTS FOR GOVERNMENT PROCUREMENT OF BRAZILIAN FEDERAL UNIVERSITIES: CONTENT ANALYSIS OF JUDGMENT OF THE BRAZILIAN AUDIT COURT}

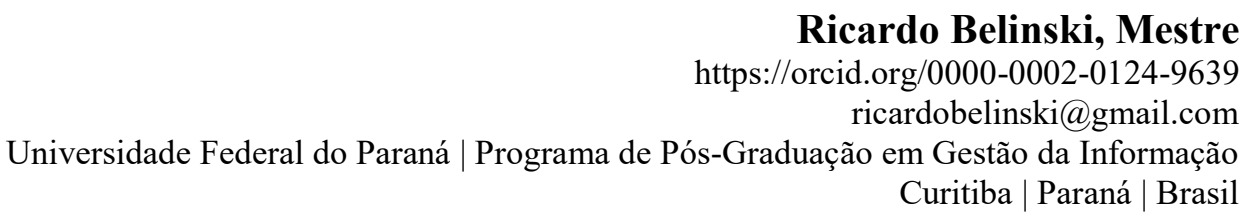

Guilherme Francisco Frederico, Doutor

https://orcid.org/0000-0002-5330-4601 guilherme.frederico@ufpr.br

Universidade Federal do Paraná | Programa de Pós-Graduação em Gestão da Informação Curitiba | Paraná | Brasil

Maria do Carmo Duarte Freitas, Doutora https://orcid.org/0000-0002-7046-6020 mcf@ufpr.br

Universidade Federal do Paraná | Programa de Pós-Graduação em Gestão da Informação Curitiba | Paraná | Brasil

Recebido em 02/junho/2020

Aprovado em 26/novembro/2020

Publicado em 01/janeiro/2021

Sistema de Avaliação: Double Blind Review

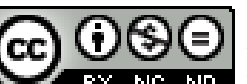

Esta obra está sob uma Licença Creative Commons Atribuição-Uso. 


\title{
RESUMO
}

A pesquisa aborda o tema compras governamentais a partir da análise de conteúdo de Acórdãos do Tribunal de Contas da União emitidos para as universidades federais brasileiras entre 2017 e 2018, abrangendo a aquisição de material de consumo e bens permanentes. Esse conteúdo apresentou exigências para a gestão universitária sobre compras governamentais, licitação e procedimentos no pregão eletrônico. Foram selecionados 41 Acórdãos dentre mais de 49 mil emitidos nesse período. Na análise de conteúdo constatou-se que houve repetição de uma mesma recomendação de auditoria para diferentes universidades, fato que evidencia a necessidade de monitoramento para implantação de práticas em gestão da informação. Os resultados apontam para exigências de aprimoramento da gestão universitária, tais como a sistematização de conhecimentos tácitos em manuais sobre os procedimentos nas compras governamentais. A investigação aborda uma área considerada de baixa materialidade pela auditoria, mas de alto risco de responsabilização personalíssima para as autoridades competentes das universidades federais brasileiras.

Palavras-chave: Gestão Pública. Entidades de Fiscalização Superior. Accountability. Compras Governamentais. Gestão da Informação.

\begin{abstract}
This paper addresses the topic of government procurement based on the content analysis of judgment issued by the Brazilian Audit Court (TCU) to Brazilian federal universities in 2017, and 2018, covering the acquisition of consumption materials, and fixed assets. This content features requirements for university administrations on government procurement, bidding, and electronic tender procedures. Forty-one judgment were selected from more than 49,000 issued during this period. The content analysis indicated a repetition of the same audit recommendation for different universities, evidencing the need for monitoring the implementation of information management practices. The results point to requirements for improvement of university administration, such as the systematic placement of tacit knowledge in manuals defining procedures for government procurement events. The investigation addresses an area considered of low significance by audits, but of high risk in personal accountability for the competent authorities of Brazilian federal universities.
\end{abstract}

Keywords: Public Administration. Supreme Audit Institutions. Accountability. Government Procurement. Information Management. 


\section{INTRODUÇÃO}

Desde o final da década de 1990, com a promulgação da Lei de Licitações e Contratos, são exigidas das autoridades competentes do governo federal brasileiro o conhecimento da legislação e jurisprudência das Entidades de Fiscalização Superior (EFS) sobre compras governamentais, como a Controladoria-Geral da União (CGU) e o Tribunal de Contas da União (TCU). O desafio do gestor público é atender simultaneamente aos princípios constitucionais da legalidade e da eficiência na licitação e compras do governo federal, abastecendo adequadamente os órgãos públicos de material de consumo e bens permanentes.

A licitação pública pressupõe uma estratégia de gestão da informação, bem como a formação continuada de servidores públicos, como os pregoeiros ${ }^{\mathrm{i}}$, além de implantação de rotinas de seleção e uso de informação para a tomada de decisão nas universidades federais brasileiras. Almeida e Sano (2018), ao abordar a questão da celeridade nas compras governamentais, consideraram quatro dimensões: i) legislação e processos de compras; ii) estrutura e organização do setor de compras; iii) sistemas de compras; e iv) recursos humanos do setor de compras.

A busca pela excelência está no contexto da desburocratização desde a década de 1970 e da aplicação dos princípios do gerencialismo na gestão pública (DE PAULA, 2005). Todavia, a ideia da excelência na gestão administrativa da universidade está presente ao menos no discurso, embora ainda como pouca operacionalização, ressaltam Gonçalves et al. (2017).

A transposição dos princípios gerenciais do setor privado ao público é um desafio complexo do gerencialismo diante da burocracia (red tape) (DENHARDT; CATLAW, 2017). Auxiliar os órgãos públicos na busca pela eficiência é uma das tarefas das EFS, como a CGU e o TCU, que auditam as compras governamentais das universidades federais (TCU, 2020b). Dias et al. (2020) abordou a importância da auditoria interna em universidade federal, sobretudo no fortalecimento da gestão e na efetividade das ações de controle das EFS, sobretudo em sintonia com as recomendações da CGU.

A relevância desse estudo está no risco de responsabilização dos gestores públicos no tocante às compras governamentais de material de consumo e bens permanentes pelas EFS, sobretudo o TCU, em uma área considerada de baixa materialidade pela auditoria (LEITÃO; DANTAS, 2016); ou seja, este estudo aborda um assunto de alto risco e baixa materialidade em auditorias da gestão universitária. As compras governamentais de produtos de consumo e 
bens permanentes representam uma baixa parcela financeira dentre as centenas de contratos das universidades federais, conforme dados da Secretaria do Tesouro Nacional (STN, 2020) e da Associação Nacional dos Dirigentes das Instituições Federais de Ensino Superior (ANDIFES, 2019).

Como o trabalho das EFS acontece depois da tomada de decisão e em fatos já consumados, há dificuldade no aprimoramento da gestão pública em tempo real (ARANTES et al., 2005); esse lapso temporal prejudica o processo de aprendizagem organizacional. Todavia este estudo apresenta um mapeamento de competências para os profissionais que atuam em compras governamentais, justamente uma das dificuldades apontadas no estudo de Montezano (2019), junto com outras dificuldades para implantação de gestão por competências em entidades públicas de ensino superior: restrições de pessoal para sua implantação, falta de apoio dos gestores e resistência dos servidores.

O assunto abordado é complexo e multifacetado, por abranger como áreas do conhecimento: administração pública, direito, gestão da informação e logística. Em especial, por direcionar estas a atividade do pregoeiro e de outras autoridades que atuam nas etapas internas e externas do pregão eletrônico (JUSTEN FILHO, 2002).

A estratégia metodológica tem cunho qualitativo e utiliza da análise de conteúdo, a partir das técnicas de Bardin (2016), para abordar o tema "licitação" e "compras governamentais" do ponto de vista da melhoria gerencial, sem entrar na discussão sobre termos jurídicos na área de licitação e contratos, tais como dolo ou culpa. Em contraposição ao predominante universo jurídico que rege a licitação pública (JUSTEN FILHO, 2002), os resultados deste estudo estão direcionados para os aspectos gerenciais sobre o uso da informação no processo de melhoria na gestão pública.

Assim, os resultados parciais da pesquisa, realizada durante os anos de 2018 e 2019, no Programa de Pós-Graduação em Gestão da Informação da Universidade Federal do Paraná, identificam as principais exigências a ser consideradas na logística das universidades federais, a partir da análise de conteúdo dos Acórdãos emitidos pelo TCU em 2017 e 2018 para as universidades federais brasileiras.

Após esta introdução, a segunda parte traz a fundamentação teórica, abordando compras governamentais, perfil profissional, gestão da informação e aprendizagem. $\mathrm{Na}$ terceira parte são apresentados os procedimentos metodológicos da análise de conteúdo de Acórdãos do TCU. Na quarta parte, na discussão e resultados, é apresentada a quantidade de 
documentos, as ideias mais frequentes, os Acórdãos emitidos para as universidades federais, as categorias de análise sobre o tema e os achados do TCU sobre compras governamentais; por fim, são apresentadas as orientações para o gestor público na área de logística e licitação. $\mathrm{Na}$ quinta parte são apresentadas as considerações finais e as limitações desse estudo.

\section{FUNDAMENTAÇÃO TEÓRICA}

A inovação e a agilidade nas compras governamentais estão relacionadas historicamente à promulgação de leis e jurisprudência das Entidades de Fiscalização Superior (EFS). A licitação exige um perfil específico do profissional que atua em compras públicas pela necessidade de que tenha conhecimento sobre a legislação e a jurisprudência e aponta como a gestão da informação pode ser gerenciada como uma boa prática em compras públicas.

\subsection{INOVAÇÃO E AGILIDADE NAS AQUISIÇÕES PELA INTERNET NAS COMPRAS GOVERNAMENTAIS}

O final da década de 1980 trouxe alterações na logística governamental brasileira, em um contexto de recriação de um governo que "funcionasse melhor e custasse menos" (DENHARDT; CATLAW, 2017, p. 216). Esses autores afirmam que, nesse racionalismo econômico, os administradores públicos buscaram consolidar a accountability e o alto desempenho por meio de melhor estruturação administrativa, como o processo de compras governamentais.

Melo Filho (2020) afirma que a Constituição Federal do Brasil, promulgada em 5 de outubro de 1988, trouxe pela primeira vez na história a exigência da necessidade de se licitar as compras governamentais. Essa menção está expressa no artigo 37, inciso XXI, que trata dos princípios e normas gerais da administração pública. O artigo 22, inciso XXVII, afirma que é competência privativa da União legislar sobre as normas gerais de licitação e contratação para as administrações públicas diretas, autárquicas e fundacionais da União, estados, Distrito Federal e municípios. Portanto, desde 1988, as aquisições públicas ficaram mais transparentes e substituíram inúmeras leis estaduais e municipais por algo válido em território nacional (MELO FILHO, 2020).

Embora tido como inconstitucional, o poder delegado à União para legislar sobre licitação para estados e municípios foi o entendimento que está vigente, de modo que se definiu que seria necessária a padronização de normas gerais de licitação para todos os entes 
da federação, afirma Justen Filho (2002). Essa realidade permanece como uma inovação, inclusive na consolidação de plataforma online para promoção de pregão eletrônico (EProcurement) no sistema Comprasnet ${ }^{\mathrm{ii}}$ no primeiro semestre de 2020.

As compras das universidades federais brasileiras são realizadas pelo Sistema Integrado de Administração de Serviços Gerais (SIASG), que foi instituído pelo Decreto n. 1.094, de 23 de março de 1994. Desse modo, foi desenvolvida uma Estratégia Geral de Logística da Administração Pública Federal que é a responsável pelo cumprimento dessas exigências (BRASIL, 2015), que devem ser feitas, preferencialmente, por meio de pregão eletrônico.

O primeiro artigo da Lei n. 10.520, de 17 de julho de 2002, permitiu a adoção da modalidade licitatória do pregão para a aquisição de bens comuns, que são aqueles cujos padrões de desempenho e qualidade possam ser objetivamente definidos em edital, por meio de especificações usuais no mercado.

$\mathrm{Na}$ etapa inicial das compras governamentais o planejamento de necessidade resulta na elaboração de um documento chamado Termo de Referência. O edital de licitação, com as regras de participação no pregão eletrônico, deve ser acompanhado do Termo de Referência, que contém as condições técnicas e gerenciais de entrega do produto licitado, incluindo formas de avaliação de fornecedores (BRASIL, 2015; BRASIL, 2017b).

A Lei n. 10.520, de 17 de julho de 2002, regulamentou o pregão eletrônico. De modo geral, o pregão eletrônico das compras governamentais, previsto pelo Decreto n. 5.450, de 31 de maio de 2005, é uma forma de leilão reverso realizado pela internet, promovido por um servidor público designado como pregoeiro. Oliveira et al. (2020), ao abordar o alinhamento estratégico entre o Plano de Desenvolvimento Institucional (PDI) e o Planejamento Estratégico de Gestão de Pessoas em uma universidade federal, trataram da necessidade de consistência entre as necessidades da instituição e o dimensionamento de sua força de trabalho. Essa área de compras governamentais é bastante complexa, pois exige habilidades (soft skills) e conhecimentos (hard skills) que são desenvolvidas durante o trabalho na função de pregoeiro.

Cabe ao pregoeiro das universidades federais dominar as regras do pregão eletrônico, buscando conhecimento dos rituais burocráticos previstos na legislação e jurisprudência do TCU para conduzir uma sessão pública. Cabe à comissão permanente de licitação evitar a dispensa de licitação, sempre que possível (TCU, 2020b). 
O governo federal está usando sistemas informatizados para controlar as etapas das aquisições públicas, no contexto de public procurement, desde meados dos anos 2000; também acompanha a execução contratual que ocorre após a sessão pública do pregão eletrônico (JUSTEN FILHO, 2002; COSTA et al., 2019).

Desde a inclusão do pregão eletrônico, o objetivo principal das compras públicas brasileiras é a redução de custos ao governo e a promoção de maior eficácia, efetividade e transparência na licitação. Há também uma dimensão de abordagens emergentes, na área de políticas públicas, como as compras sustentáveis e o uso do pregão em reserva de mercado governamental para as pequenas e microempresas (COSTA et al., 2019).

Em visão mais ampla da evolução da legislação sobre licitação é importante mencionar a dimensão da inovação no cenário nacional. A inovação é um dever do Estado, afirmam Mulgan e Albury (2003), porque os serviços públicos devem ser mais eficientes. No Brasil, com a publicação da Emenda Constitucional n. 85, de 26 de fevereiro de 2015, houve a inclusão do parágrafo único afirmando que o Estado estimulará a formação e o fortalecimento da inovação nas empresas, bem como nos demais entes, públicos ou privados, a constituição e a manutenção de parques e polos tecnológicos e de demais ambientes promotores da inovação, a atuação dos inventores independentes e a criação, absorção, difusão e transferência de tecnologia.

A Lei n. 13.243, de 11 de janeiro de 2016, instituiu no país um novo Marco Legal para Ciência, Tecnologia e Inovação, com a alteração de alguns dispositivos da Lei n. 10.973/2004, conhecida como Lei da Inovação. Uma das novidades foram os procedimentos simplificados para a aquisição de bens e serviços comuns com características de inovação (TCU, 2020a; MCTIC, 2020). Para acompanhar as inovações incrementais nas aquisições de bens e serviços públicos se faz necessário formar profissional com perfil e conhecimentos tecnológicos específicos.

\subsection{PERFIL DO PROFISSIONAL DE COMPRAS PÚBLICAS}

$\mathrm{Na}$ área de licitação e compras governamentais é relevante estudar a carreira na gestão pública porque Silva et al. (2019) afirmam que isto constitui fator crucial para a valorização do servidor, por propiciar motivação, contribuir na melhoria da qualidade de vida e segurança no trabalho, além de nortear a formação pessoal no desenvolvimento de aptidões técnico-funcional. 
O ambiente de desenvolvimento contínuo na carreira de servidores das universidades federais foi alterado pelo novo plano de carreira dos cargos técnico administrativos em educação com a Lei n. 11.091, de 12 de janeiro de 2005, denominado por PPCTAE. Essa lei aumentou a remuneração do servidor pela progressão por capacitação profissional em quatro níveis (A até E) por meio de cursos de 90 até 180 horas, além de avultar a remuneração pela qualificação por meio de estudos regulares (acréscimos de 5\% até 75\% sobre o vencimento básico) pela educação formal em graduação, especialização, mestrado e doutorado (GONÇALVES et al., 2017).

Em comparação aos profissionais de procurement no setor privado, os profissionais de aquisições no setor governamental possuem perspectivas mais estreitas sobre as práticas logísticas, afirma Larson (2009). Isso significa menor atenção do servidor público aos fatores gerenciais da logística, como eficiência, custo e alianças estratégicas entre comprador e vendedor, previstos em manuais de administração de materiais e logística (BOWERSOX, 2006; BALLOU, 2006; CHOPRA, MEINDL, 2016).

No setor público, há maior ênfase no cumprimento da legislação em vigor sobre licitação, ou seja, há uma primazia do princípio constitucional da legalidade, afirma Larson (2009). O profissional de aquisição no setor governamental é essencialmente diferente em seus objetivos e suas práticas logísticas, afirmam McCue e Pitzer (2005). Os profissionais do setor público são guiados por leis e regulamentos (LARSON, 2009). Esse paradoxo marca o embate entre os princípios constitucionais da legalidade e da eficiência na gestão pública. Afinal, como ter eficiência logística nos limites previstos em lei? A gestão da informação e do conhecimento da jurisprudência presente nos Acórdãos do TCU exige investimento em processos e pessoas (GONÇALVES et al., 2017; TCU, 2020a).

O conhecimento é o resultado de um rol de capacidades e competências que uma organização desenvolve para atingir seus objetivos, geralmente fruto da transformação do conhecimento tácito das pessoas em conhecimento explícito para a gestão. Muitas organizações reconhecem a "importância do conhecimento que pode ser acumulado em suas atividades, tarefas e operações" durante anos, os quais podem ser partilhados entre as pessoas (CHOO, 2006, p. 127). É a gestão da informação que permite a transformação de dados e informações em conhecimento, afirma Davenport (1998).

Goez (2018, p. 123) afirma que há uma "relação direta entre o conceito de competência com o aprendizado ao longo da vida (lifelong learning) e sua importância na 
Sociedade da Informação" no acesso, busca e uso da informação para a tomada de decisões. A aprendizagem envolve dois diferentes processos: um processo externo de interação do indivíduo e seu ambiente social, cultural e material, e um processo psicológico interno de elaboração e aquisição de conhecimentos (ILLERIS, 2013).

Esse processo de transformar dados e informações em conhecimento tem a gestão da informação como uma importante ferramenta gerencial, haja vista que os administradores públicos são e devem ser responsabilizados a partir de conteúdo presente em normas, instruções normativas e jurisprudência do TCU (DENHARDT; DENHARDT, 2007), em um ambiente de accountability no serviço público.

Cabe aos profissionais que atuam em logística e licitação públicas transformar dados e informação em conhecimento. Os sinais, quando fisicamente estruturados e selecionados, podem se transformar em dados que, cognitivamente estruturados, dotados de significado e significância, podem se transformar em informação. Resumindo, o conhecimento é fruto de “informação dotada de crença e justificação”, explica Choo (2006, p. 132).

O monitoramento pelas EFS visa orientar, educar e prevenir os riscos na gestão pública, sob risco de responsabilização das autoridades competentes (ARANTES et al., 2005). Utilizar o resultado de um ciclo de auditoria para a melhoria em anos subsequentes na gestão pública é um dos objetivos das EFS, preconiza o manual de orientações técnicas da atividade de auditoria interna governamental do Poder Executivo Federal (BRASIL, 2017a). Esses saberes, uma vez consolidados no profissional de compras, capacita-o a documentar e monitorar as boas práticas e gerenciar as informações oriundas da atividade de pregoeiro.

\subsection{PRÁTICAS DE GESTÃO DA INFORMAÇÃO EM COMPRAS PÚBLICAS}

O ambiente da informação em sua totalidade considera os valores e as crenças organizacionais sobre informação (DAVENPORT, 1998). Assim como, os profissionais utilizam a informação em seus processos de trabalho, as barreiras ao fluxo e compartilhamento de informação, além dos sistemas de informação e as novas tecnologias.

No ciclo de vida da informação os ativos físicos, tecnológicos e humanos fazem uso da informação que dão suporte a processos que mantêm as operações da instituição, afirma Sêmola (2003); para esse autor os processos são: manuseio, armazenamento, transporte e descarte da informação, com as seguintes características: confidencialidade, integridade, disponibilidade, autenticidade e legalidade. Detlor (2010) complementa que o ciclo de vida da 
informação requer a gestão da informação e aponta como etapa o armazenamento, distribuição e utilização da informação nas organizações. Best (2010) afirma que a disseminação das informações internas e externas auxiliam no desempenho organizacional.

Cooper e Schindler (2011) ampliam a discussão com ênfase no gestor e comenta que há uma hierarquia entre os tipos de tomadores de decisão baseados em informação, como segue: i) no nível básico são intuitivos, baseiam-se em experiências anteriores ou em instinto; ii) no nível médio são padronizados, com algumas decisões baseadas em pesquisa, utilizam metodologias testadas e aprovadas previamente com dados limitados; e iii) no nível superior são visionários, em que cada decisão é guiada por pesquisa, com inovação na combinação de metodologias de pesquisa e com acesso a dados e achados em todas as instâncias da organização.

O nível de conhecimento para tomada de decisão requer aprendizagem. Senge (2011) dizia que a aprendizagem é um processo eterno, que nunca se chega a um lugar, porque sempre há o aprimoramento. "Quanto mais se aprende, mais nos conscientizamos de nossa ignorância”, explicava Senge (2011, p. 44) em sua quinta disciplina sobre o pensamento sistêmico, que integra as outras disciplinas: domínio pessoal, modelo mental, visão compartilhada e aprendizagem em equipe.

Com o advento da internet surgiram outras oportunidades de ampliar os conhecimentos no ambiente de trabalho. Siemens (2018), em sua teoria de aprendizagem denominada Conectivismo, afirma que a internet possibilita acesso em tempo real a repositórios de informação que favorecem a aprendizagem. Outro autor, Bell (2011), resumia o Conectivismo como uma dentre as teorias de aprendizagem mediadas pela tecnologia. A aplicação do Conectivismo de George Siemens foi abordada por Lima et al. (2020), em seu estudo em instituições públicas de ensino superior sobre as abordagens metodológicas e seus impactos no uso de mídias sociais. Para Lima et al. (2020, p. 121), o Conectivismo se refere "à integração dos princípios das teorias do caos, de rede, da complexidade e da autorregulação".

A aprendizagem e as práticas de gestão da informação em compras públicas requerem a consulta aos Acórdãos do TCU que é facilitada pela existência de um portal online governamental, que está inserido no movimento de dados abertos do governo (OPEN GOVERNMENT WORKING GROUP, 2007). Esses documentos materializam a accountability legal, porque resultam de uma auditoria de conformidade à legislação e 
jurisprudência vigente sobre as compras governamentais e que devem ser conhecidos pelos gestores públicos (ROMZEK; INGRAHAM, 2000). Para isso, é preciso considerar o ciclo de vida da informação, desde sua criação até seu descarte (Sêmola, 2003).

Assim, os portais governamentais, como o do TCU, funcionam como um ponto centralizado de acesso a documentos de prestação de contas emitidos pelos órgãos de controle e, se consultados por pesquisadores e cidadãos, afirma Lourenço (2015), favorecem a accountability. Ao analisar os tipos de accountability aplicadas ao setor público - hierárquica, profissional, legal e política, os autores Duarte et al. (2018) identificaram que a maioria dos estudos sobre a prestação de contas estão classificados na abordagem da accountability legal e da accountability política, indicando que a fonte de controle está localizado no ambiente externo, geralmente no cumprimento de leis e ao oferecimento de resposta aos órgãos de controle.

Um dos elementos a se considerar nas auditorias foi o Programa de Reestruturação e Expansão das Universidades Federais (REUNI), instituído pelo Decreto $\mathrm{n}^{\mathrm{o}} 6.096$ de 24 de abril de 2007, que repentinamente expandiu a oferta de vagas no ensino superior e exigiu um maior volume de compras governamentais para suportar o aumento da infraestrutura sem um planejamento prévio e amadurecimento da comunicação interna sobre as metas e objetivos a longo prazo (ABREU; MARRA, 2019).

Em suma, esta pesquisa utilizou as seguintes categorias de contexto e de análise, segundo Bardin (2016), no tocante à gestão da informação: aprendizagem, ciclo de vida da informação e transparência.

\section{PROCEDIMENTOS METODOLÓGICOS}

Esta é uma pesquisa qualitativa, documental e exploratória, derivada de estudo durante o mestrado em Gestão da Informação. A pesquisa qualitativa pressupõe a escolha correta de métodos e teorias oportunas, no reconhecimento e na análise de diferentes perspectivas como parte de produção do conhecimento (CRESWELL, 2003; FLICK, 2004). A epistemologia adotada nesta pesquisa documental foi o objetivismo em uma perspectiva filosófica de póspositivismo (CROTTY, 1998), em que foi aplicada a técnica de análise de conteúdo (BARDIN, 2016) em documentos do TCU. 
Foram coletados os Acórdãos emitidos para as universidades federais e que trataram tão somente de compras governamentais de material de consumo e bens permanentes em 2017 e 2018 no site do TCU (http://www.tcu.gov.br) no segundo semestre de 2018.

Uma das características dos Acórdãos do TCU é a presença de múltiplas fontes de evidências, incluindo entrevistas e respostas de gestores públicos das universidades às questões de auditoria. Esses documentos possuem a característica de apresentar a análise de eventos por meio da triangulação de múltiplas fontes de evidência: documentos, entrevistas, observação, validação de sistemas informatizados, segundo orientações da International Organization of Supreme Audit Institutions (INTOSAI, 2016).

Para Bardin (2016), a escolha do corpus de análise compreende a etapa de pré-análise e leitura flutuante. Este estudo considerou os Acórdãos emitidos para as 69 universidades federais existentes em dezembro de 2018 e que foram monitoradas em auditoria externa em 2017 e 2018 no tema compras governamentais de material de consumo e bens permanentes. Um corpus é delineado pelos critérios de relevância, homogeneidade e sincronicidade, afirmam Bauer e Aarts (2015).

Segundo a Associação Nacional dos Dirigentes das Instituições Federais de Ensino, em 2019, as 69 universidades federais brasileiras atuavam em 298 municípios, tinham 1.333.826 estudantes matriculados; 199.244 mestrandos e doutorandos; 398.100 vagas na graduação; 5.118 cursos de graduação (ANDIFES, 2019). Em 2019, para sustentar essa estrutura educacional foram destinados quase 7 bilhões de reais para verba de custeio, dentre os quais a menor parte está destinada às compras governamentais de material de consumo e bens permanentes.

\subsection{PASSOS PARA PRÉ-ANÁLISE DE CONTEÚDO}

Pela natureza processual do método de análise de conteúdo, as etapas de coleta e análise de dados aconteceram simultaneamente (BARDIN, 2016). Em consulta ao site do TCU foi constatado que, no ciclo 2017 e 2018, foram emitidos Acórdãos para 28 das 69 universidades federais sobre a logística de bens de consumo e materiais permanentes. A análise de conteúdo desses documentos foi auxiliada por computador com o uso de CAQDAS (Computer-assisted qualitative data analysis software) (KELLE, 2015), adotando-se o software NVivo para codificação e análise. Foram identificadas as unidades de registro (palavras e temas) relacionadas às compras governamentais. 
Para compreender o conteúdo dos documentos emitidos pelos órgãos de controle, foi consultado o Manual de Auditoria Operacional do TCU, que contém princípios e padrões que orientam a realização dos trabalhos de fiscalização externa pela aplicação de normas internacionais ao trabalho de auditoria operacional das unidades técnicas do tribunal, publicado na primeira versão em 1998 e revisto nos anos de 2000 e 2010 (TCU, 2010; TCU, 2020a). A novidade desse manual foi a abordagem de que o ciclo de realização da modalidade auditoria operacional no setor público deve estar alinhado às Normas Internacionais das Entidades Fiscalizadoras Superiores (ISSAI) da International Organization of Supreme Audit Institutions (Intosai).

O trabalho do TCU aborda a auditoria operacional e a auditoria de conformidade, podendo haver sobreposição entre esses dois tipos de trabalho (TCU, 2020a). Por um lado, a auditoria operacional abordou questões complexas e subjetivas de economicidade, eficiência, eficácia, efetividade e equidade na gestão pública, resultando em maior flexibilidade na escolha dos temas, objetos de auditoria, métodos de trabalho e comunicação de resultados (TCU, 2020b).

O objetivo da auditoria operacional é contribuir para a melhoria administrativa da gestão pública, a postura do auditor é a de um consultor de políticas públicas em uma atitude de parceria e cooperação. Os achados de auditoria operacional são resultantes da comparação entre a situação encontrada e os critérios previamente definidos. Contém os seguintes atributos: critério (o que deveria ser), condição (o que é), causa (razão do desvio com relação ao critério) e efeito (consequência da situação encontrada), segundo orientações da Intosai (2016).

Por outro lado, a auditoria de conformidade apresenta conclusões objetivas sobre a conformidade das transações com leis e regulamentos, além da inadequação dos controles internos, de atos ilegais ou fraude, ou seja, seu objetivo é verificar se o gestor público fez os atos administrativos dentro do princípio constitucional da legalidade, sendo que a postura do auditor é similar à de um juiz como agente externo independente e imparcial (TCU, 2020b).

Os documentos emitidos pelo TCU foram analisados a partir das práticas da gestão da informação (DETLOR, 2010; BEST, 2010) e do ciclo de vida da informação (SÊMOLA, 2003). Assim foram identificadas as universidades auditadas, os Acórdãos emitidos para esse rol, bem como identificada a prevalência de uma auditoria de conformidade. 


\section{RESULTADOS E DISCUSSÃO}

A discussão inicia pela apresentação de um passo a passo da inferência e interpretação de conteúdo (BARDIN, 2016). Diante dos inúmeros documentos emitidos anualmente pelo TCU, cabe à administração pública implantar sistemas de gestão da informação para transformar dados e informação em conhecimento (DAVENPORT, 1998).

\subsection{ACÓRDÃOS DO TCU EMITIDOS EM 2017 E 2018}

Em consulta ao site do TCU foram localizados o total de 49.933 Acórdãos emitidos em 2017 e 2018, conforme o quadro 1. Esses documentos foram direcionados para vários órgãos públicos brasileiros, abordando diversos assuntos, entre eles a licitação.

Quadro 1 Total de Acórdãos emitidos pelo TCU (2017-2018)

\begin{tabular}{|c|c|c|}
\hline ANO & TCU & DOCUMENTOS \\
\hline 2017 & Primeira Câmara & 11.255 \\
\hline 2017 & Segunda Câmara & 10.378 \\
\hline 2017 & Plenário & 2.925 \\
\hline Total & & $\mathbf{2 4 . 5 5 8}$ \\
\hline 2018 & Primeira Câmara & 12.909 \\
\hline 2018 & Segunda Câmara & 10.058 \\
\hline 2018 & Plenário & 2.408 \\
\hline Total & & $\mathbf{2 5 . 3 7 5}$ \\
\hline & Total Geral & $\mathbf{4 9 . 9 3 3}$ \\
\hline
\end{tabular}

Fonte: Tribunal de Contas da União (2019).

No site do TCU, os documentos consultados mostram os acórdãos que foram emitidos e mencionaram a palavra "universidade". Desse rol foram extraídos os documentos que trataram de universidades federais, incluindo-se recomendações ao Ministério do Planejamento, Desenvolvimento e Gestão, atual Ministério da Economia, responsável pelas compras governamentais, resultando em mais de 11 mil documentos, 23\% do total. Em leitura flutuante, conforme Bardin (2016), foram selecionados 41 documentos para essa análise de conteúdo (Quadro 2).

Uma das características presentes nos Acórdãos foi a constante referência a decisões anteriores, ou seja, a consulta a uma base de conhecimento pelos ministros do TCU. Para se compreender o assunto compras governamentais, em uma visão sistêmica (SENGE, 2011), foi necessária a consulta ao conteúdo de outros Acórdãos, haja vista que o TCU aborda os órgãos públicos sem distinção de suas especificidades. 
Quadro 2 Acórdãos do TCU emitidos para universidades (2017-2018)

\begin{tabular}{|c|c|c|c|c|}
\hline ANO & TCU & ACÓRDÃOS & AMOSTRA & QUANTIDADE \\
\hline 2018 & Primeira Câmara & 5.516 & $1291-1971$ & 2 \\
\hline 2018 & Segunda Câmara & 180 & $6326-8020-8021-9364-10194$ & 5 \\
\hline 2018 & Plenário & 303 & $\begin{array}{c}0538-1033-1451-1745-1796-2076 \\
-2587-2588-2681-2889\end{array}$ & 10 \\
\hline 2017 & Primeira Câmara & 4.122 & - & 0 \\
\hline 2017 & Segunda Câmara & 1.079 & $\begin{array}{c}1620-5235-5428-5810-7868-7869 \\
-7872-7884-9316-9456-9565\end{array}$ & 11 \\
\hline 2017 & Plenário & 243 & $\begin{array}{c}0367-0581-0592-0604-0917-0918 \\
-1003-1056-1469-1837-2141- \\
2434-2593\end{array}$ & 13 \\
\hline & Total & $\mathbf{1 1 . 4 4 3 ( 2 3 \% )}$ & & $\mathbf{4 1}$ \\
\hline
\end{tabular}

Fonte: Baseado no website do Tribunal de Contas da União (2019).

\subsection{AS UNIDADES DE REGISTRO MAIS FREQUENTES}

As unidades de registro (palavras e frases) foram identificadas, conforme Bardin (2016), usando-se consulta à frequência de palavras nos 41 documentos por meio do software NVivo; no qual as palavras mais frequentes foram agrupadas por palavras "derivadas". Como resultado, foram identificados três eixos de análise:

a) A responsabilidade do reitor ou autoridade competente pela elaboração de políticas de compras governamentais, sendo responsável pelos riscos nas aquisições, pela nomeação de servidores por meio de portarias, além de precisar atender às determinações das EFS, sanando os vícios e indícios de ilegalidades na licitação;

b) As práticas e procedimentos adotados pelo pregoeiro na sessão pública com as empresas licitantes, a validação dos preços e prazos previstos no edital e no termo de referência, bem como na responsabilidade individual de conhecer e aplicar a jurisprudência do TCU no pregão eletrônico, como assegurar o direito ao recurso das empresas licitantes na etapa de habilitação do pregão e da validação das propostas comerciais;

c) A necessidade da etapa de planejamento antes da sessão do pregão eletrônico, em que é elaborado o Termo de Referência e estimada a programação de compras, preferencialmente no Sistema de Registro de Preços; essa etapa prevê estudos sobre as características dos produtos que serão aceitos pelo pregoeiro no certame.

\subsection{O CONTEÚDO DA JURISPRUDÊNCIA DO TCU SOBRE COMPRAS GOVERNAMENTAIS}

Nos Acórdãos foram destacadas a responsabilidade do pregoeiro e das autoridades competentes das universidades federais. Para o TCU, durante o pregão eletrônico, a autoridade competente é: i) responsável pela fiscalização da licitação, dos preços e dos 
procedimentos adotados pelo pregoeiro; e ii) responsável pela supervisão dos poderes delegados ao pregoeiro, à equipe de apoio e aos responsáveis pela pesquisa de preços e fiscalização de contratos por meio de ativo controle interno (Acórdão 1.659/2015 TCU Plenário).

Como exemplo da complexa responsabilização pelos atos administrativos na gestão universitária, a auditoria, em um determinado caso, não recebeu a informação sobre o rol de todos os responsáveis que desempenharam durante um exercício fiscal as naturezas de responsabilidade definidas no art. 10 da Instrução Normativa 63/2010 do TCU (Acórdão 1.971/2018 TCU Primeira Câmara).

Sobre a formalização das responsabilidades, houve menção à necessidade de se definir o papel de cada servidor no processo de compras governamentais, com a emissão de sua respectiva portaria de nomeação. Cabe ao reitor delegar e fiscalizar todos os atos e fatos administrativos da universidade federal (Acórdão 1.659/2015 TCU Plenário), ou seja, a delegação de responsabilidade não exime a reitoria da responsabilidade da prestação de contas anuais, nem de manter um controle ativo de todos os atos administrativos em sua universidade.

O plano e planejamento de compras foram solicitados em auditoria, sobretudo no contexto de dispensa de licitação e de compras emergenciais. Resumidamente, foi identificado o foco na auditoria de conformidade.

\subsection{UNIDADES DE CONTEXTO PARA ANÁLISE}

A partir do conteúdo dos Acórdãos foram identificadas as categorias de contexto e de análise relacionadas à gestão da informação: aprendizagem, ciclo de vida da informação e transparência (BARDIN, 2016). A pesquisa identificou as seguintes categorias:

a) Logística e compras governamentais: estratégia, produtos, aquisição, controles e sustentabilidade.

b) Administração pública: Lei de Acesso à Informação, prestação de contas e licitação e contratos.

c) Lei de Acesso à Informação sobre os Acórdãos do TCU foram identificadas exigências sobre a internet, os documentos, o tempo, a disponibilidade, os planos, a regularidade, o perfil e nomeação de chefias, a prestação de contas, o rol de responsáveis na universidade e os documentos de auditoria.

d) Transparência e divulgação dos documentos que integram o processo de aquisição: solicitação de aquisição, estudos técnicos preliminares, estimativas de preços, pareceres técnicos e jurídicos na internet (Acórdão 538/2018 TCU Plenário). 
Entre os documentos, foi solicitada a divulgação do plano anual de aquisições no site da instituição, que deve estar aprovado pela mais alta autoridade da organização (Acórdão 2.889/2018 TCU Plenário), que são os órgãos superiores colegiados nas universidades federais.

Sobre os responsáveis pela gestão universitária foi recomendada a publicação da decisão quanto à regularidade das contas proferida pela EFS no site da universidade; também foi solicitada a divulgação da agenda de compromissos públicos do dirigente responsável pelas aquisições, geralmente o pró-reitor de administração (Acórdão 538/2018 TCU Plenário).

Foi identificado que a responsabilidade sobre as compras governamentais recaiu sobre a reitoria, os pró-reitores e as pessoas integrantes de órgãos superiores colegiados, conforme indicado no organograma de cada universidade (Acórdãos 2.034/2017 TCU Plenário). Tendo em vista a responsabilização personalíssima sobre as compras governamentais, o TCU recomendou a atribuição a um comitê, integrado por representantes dos diversos setores da universidade, a responsabilidade por auxiliar a alta administração nas decisões relativas às aquisições, com objetivo de buscar o melhor resultado para a universidade como um todo (Acórdão 2.889/2018 TCU Plenário).

Embora haja obrigação de licitar, conforme Lei de Licitação e Contratos (Lei n. 8.666/1993), o TCU identificou grande número de compra direta por dispensa de licitação em $75 \%$ das licitações em geral, em estudo realizado com 14 organizações públicas, incluindo universidades, entre janeiro de 2016 até agosto de 2017, correspondendo em valores a 40\% do montante (Acórdão 1.796/2018 TCU Plenário). Ou seja, sempre que possível, buscou-se a dispensa de licitação nas compras governamentais, sem a definição de uma política de gestão de riscos nas aquisições e de um plano anual de aquisições, quando foi solicitado em auditoria.

Assim foram constatadas pelo TCU as seguintes fragilidades nas compras governamentais nas universidades federais: a ausência de política de gestão de riscos; a não realização de gestão de riscos das contratações; a carência de iniciativas para capacitação dos gestores das áreas de contratações em gestão de riscos; o não monitoramento das contratações diretas sem licitação; a não realização de estudos técnicos preliminares; a não elaboração de plano anual de contratações; a ausência de medidas para evitar a realização de contratações emergenciais; a não avaliação do nexo efetivo entre a natureza da instituição e o objeto 
contratado, além de comprovada compatibilidade com preços de mercado, nas contratações enquadradas no inciso XIII do art. 24 da Lei 8.666/1993 (Acórdão 1.796/2018 TCU Plenário).

\subsection{PARADOXO ENTRE O PRINCÍPIO DA LEGALIDADE E DA EFICIÊNCIA NAS COMPRAS GOVERNAMENTAIS}

A análise de conteúdo dos Acórdãos do TCU apontou que o sistema de compras das universidades federais, que fizeram parte desta pesquisa, não consideraram as informações presentes na jurisprudência do TCU emitidas para outros órgãos públicos. Houve repetição de assuntos tratados anteriormente pela EFS em um ciclo contínuo de recomendação disponível no portal do TCU. Essa é uma evidência de que a informação das EFS não foi utilizada para a melhoria da gestão pública (GONÇALVES et al., 2017).

Em consulta aos Acórdãos do TCU emitidos em 2017 e 2018 foram observadas as seguintes exigências: i) a presença de recorrentes recomendações da auditoria no planejamento estratégico, tático e operacional de logística das universidades federais; ii) a exigência de cumprimento legal nos atos administrativos de suporte à gestão universitária; iii) a identificação de pontos relevantes da gestão que seriam auditados no próximo ciclo de auditoria; e iv) a identificação de competências profissionais daqueles que atuam no setor de compras e licitação das universidades.

No conteúdo de Acórdãos do TCU ficou evidente a predominância do princípio constitucional da legalidade em detrimento ao princípio da eficiência. O fiel cumprimento da legislação em detrimento de busca de novas formas de contratação foi verificado pelo TCU, no qual se constatou que a logística no setor governamental está inserida em um ambiente de cultura organizacional pouco voltada à inovação (TCU, 2017):

a) apego excessivo às normas e aos processos burocráticos;

b) descontinuidade administrativa, a cada mudança de gestão;

c) alto grau de resistência a mudanças, de qualquer natureza;

d) fixação de metas que implicam alocação integral dos recursos existentes para atividades de rotina;

e) ambiente com baixa tolerância a erros, resultando em medo dos servidores de se exporem a críticas;

f) dificuldade para realizar ações experimentais e avaliar seu benefício. 
Essas barreiras foram citadas no Referencial Básico do Programa de Inovação, publicado pelo TCU, e influenciam a inovação na dimensão administrativa e organizacional, que são mudanças em estruturas e rotinas de funcionamento interno (TCU, 2017).

O conteúdo dos Acórdãos pesquisados aponta para o apego às normas e ao processo burocrático antes, durante e depois do pregão eletrônico, sob risco de aplicação de multas em decorrência da responsabilização personalíssima do pregoeiro e da autoridade competente.

Por exemplo, em consulta ao site do TCU foi constatada a emissão de 611 Acórdãos nos últimos cinco anos (2015 a 2019) que englobam, ao mesmo tempo, o assunto "multa" e "pregoeiros", englobando todos os órgãos auditados, inclusive as universidades. Assim, temse a necessidade de se implantar práticas de gestão da informação, como as descritas por Sêmola (2003), para uso do conteúdo dos documentos emitidos pelas EFS. Uma das características identificadas neste estudo foi a gestão colegiada das universidades federais, mas com responsabilização personalíssima do pregoeiro, da autoridade competente e do reitor.

Um ambiente inovador, com maior tolerância a erros nas compras governamentais, exige conhecimento da jurisprudência do TCU, que emite mais de 24 mil documentos anualmente. Apenas um processo sistemático de gestão da informação será capaz de fornecer as corretas informações ao pregoeiro e às autoridades competentes nas várias etapas da licitação, resultando em aprendizagem (CHOO, 2006).

A seguir são apresentadas exigências aos atores das compras governamentais: pregoeiro, responsável pela pesquisa de preços e pela elaboração do Termo de Referência, autoridade competente para adjudicação e homologação de certame.

\subsection{EXIGÊNCIAS AOS ATORES DAS COMPRAS DAS UNIVERSIDADES FEDERAIS}

Em consulta ao conteúdo de Acórdãos do TCU identificaram-se os principais objetivos logísticos a serem incorporados na estratégia da gestão universitária brasileira, expressos no quadro 3.

As exigências expressas no Quadro 3 evidenciam a predominância de uma Auditoria de conformidade (ISSAI 400) que, de acordo com a International Organisation of Supreme Audit Institutions (Intosai), está focada em determinar se as atividades estão, em todos os aspectos materiais, em conformidade com os preceitos determinados pelos responsáveis pela governança pública (LEITÃO; DANTAS, 2016). 
Quadro 3 Exigências nas compras governamentais em achados do TCU

\begin{tabular}{|c|c|c|}
\hline Item & Objetivo logístico & Acórdão TCU \\
\hline 1 & $\begin{array}{c}\text { Aprimorar os processos de aquisições que dão suporte ao ensino, pesquisa, } \\
\text { extensão e gestão. }\end{array}$ & 1796/2018 TCU Plenário \\
\hline 2 & Assegurar a existência de mecanismos de gestão das aquisições públicas. & 2681/2018 TCU Plenário \\
\hline 3 & $\begin{array}{c}\text { Atender às demandas de auditoria interna e externa sobre licitação e } \\
\text { contratos. }\end{array}$ & 6326/2018 TCU 2a Câmara \\
\hline 4 & Criar infraestrutura para gestão da ética administrativa no serviço público. & 581/2017 TCU Plenário \\
\hline 5 & Criar modelo de controle e accountability nas aquisições. & 604/2017 TCU Plenário \\
\hline 6 & Definir política de compras e de estoques. & $\begin{array}{l}\text { 5810/2017 TCU 2a Câmara } \\
\text { 2588/2018 TCU Plenário }\end{array}$ \\
\hline 7 & Desenvolver as competências dos servidores e dos gestores universitários. & 1796/2018 TCU Plenário \\
\hline 8 & Divulgar os princípios de ética e conduta nas aquisições. & 581/2017 TCU Plenário \\
\hline 9 & Elaborar modelo de governança de contratações. & 5810/2017 TCU $2^{\mathrm{a}}$ Câmara \\
\hline 10 & Elaborar Plano de Gestão de Contratos. & 6326/2018 TCU $2^{\text {a }}$ Câmara \\
\hline 11 & Elaborar Plano de Gestão de Riscos e Controles nas Aquisições. & $\begin{array}{l}\text { 1796/2018 TCU Plenário } \\
\text { 2681/2018 TCU Plenário }\end{array}$ \\
\hline 12 & $\begin{array}{c}\text { Elaborar Plano de Gestão Estratégica, Tática e Operacional das } \\
\text { contratações. }\end{array}$ & 2588/2018 TCU Plenário \\
\hline 13 & Elaborar Plano de Sustentabilidade e Plano de Logística Sustentável. & 10562017 TCU Plenário \\
\hline 14 & $\begin{array}{l}\text { Estabelecer modelo de prestação de contas e acompanhamento de } \\
\text { recomendações dos órgãos de controle. }\end{array}$ & 6326/2018 TCU 2a Câmara \\
\hline 15 & Estabelecer modelo de responsabilização da autoridade competente. & $\begin{array}{l}\text { 367/2017 TCU Plenário } \\
\text { 581/2017 TCU Plenário }\end{array}$ \\
\hline 16 & $\begin{array}{c}\text { Estabelecer modelo de transparência ativa e passiva dos atos } \\
\text { administrativos. }\end{array}$ & $\begin{array}{l}\text { 6326/2018 TCU 2a Câmara } \\
\text { 1469/2017 TCU Plenário }\end{array}$ \\
\hline 17 & Promover a previsão e planejamento de demanda anual de aquisições. & 2593/2017 TCU Plenário \\
\hline 18 & $\begin{array}{l}\text { Promover transparência, responsabilidade e acompanhamento da prestação } \\
\text { de contas. }\end{array}$ & $\begin{array}{l}\text { 6326/2018 TCU } 2^{\text {a }} \text { Câmara } \\
\text { 1796/2018 TCU Plenário }\end{array}$ \\
\hline 19 & Segregar as funções na área de gestão de aquisições. & $\begin{array}{l}\text { 6326/2018 TCU 2 } 2^{\mathrm{a}} \text { Câmara } \\
\text { 367/2017 TCU Plenário }\end{array}$ \\
\hline 20 & Zelar pelos procedimentos na sessão pública do pregão eletrônico. & $\begin{array}{l}\text { 6326/2018 TCU 2a Câmara } \\
\text { 2593/2017 TCU Plenário }\end{array}$ \\
\hline
\end{tabular}

Fonte: elaborado pelos autores (2020).

No tocante ao desenvolvimento de competências de técnicos administrativos em educação foi constatado que a política de capacitação com incentivos financeiros, com o advento do PPCTAE, desde 2005, nem sempre esteve alinhada às necessidades da área de licitação e compras governamentais, evidenciada pelas constantes recomendações do TCU sobre complexas atividades gerenciais, tais como pesquisa de preços inadequadas, conduta irregular de pregoeiro em sessão pública, na aceitação de proposta comercial sem o devido atendimento técnico ao Termo de Referência do Edital de Licitação.

Os resultados apontam para a necessidade de alinhar a formação profissional de servidores públicos que atuam nas universidades federais com as necessidades da área de licitação e compras governamentais, como os pregoeiros, fiscais de contrato e responsáveis 
pela elaboração do Termo de Referência, prevista no Decreto Federal n. 5.450/2005, de forma prática e não apenas conceitual (GONÇALVES et al., 2017).

\section{CONSIDERAÇÕES FINAIS}

Desde o final da década de 1980, com a promulgação da Carta Magna, as compras públicas brasileiras visam implantar modelo de compras governamentais de excelência, adaptando práticas usuais de empresas privadas de excelência, tais como capacitação de recursos humanos nas funções de procurement (sobretudo o pregoeiro), implantação de plano anual de compras de material de consumo e bens permanentes, a adoção de plataforma online para sessão de pregão eletrônico, o aprimoramento da legislação na área de compras governamentais.

As Entidades Fiscalizadoras Superiores (EFS), como o Tribunal de Contas da União (TCU), atuam na auditoria da área de compras governamentais, logística e licitação. Seu acervo de Acórdãos, disponíveis online, constitui uma fonte de informação para delinear as melhores práticas do gestor público de excelência, bem como evitar mesmas falhas presentes em outras universidades federais. Foram evidenciadas as exigências para as compras governamentais, as melhores práticas para os pregoeiros e autoridade competente, bem como os pontos de interesse que devem ser considerados no planejamento dos controles internos.

Este estudo qualitativo, com análise de conteúdo em documentos, abordou um assunto complexo e multidisciplinar nas áreas de direito, administração pública e gestão da informação que oferecem pistas para a gestão de competências em universidades, sobretudo do pregoeiro. O foco deste estudo está na gestão da informação, buscando aspectos de melhoria gerencial, apenas citando a legislação e jurisprudência do TCU, sem adentrar no campo jurídico pertinente à área de licitação e contratos.

Entre os achados da pesquisa estão a exigência pela elaboração de orientações táticas e operacionais, tais como: manual de princípios éticos e de conduta nas aquisições, modelo de governança de contratações, plano de gestão de contratos, plano de gestão de riscos nas aquisições, plano de gestão tática e operacional das aquisições, plano de sustentabilidade e plano de logística sustentáveis e plano de demanda anual de aquisições.

A inexistência desses manuais no momento da auditoria significa que ainda havia processos gerenciais que não estavam estruturados e sistematizados, não eram objetivos e não tinham metas e objetivos definidos na área de compras governamentais e licitação. Eram 
atividades existentes, manifestadas pelo conhecimento tácito de servidores públicos federais que detinham um conhecimento e um modus operandi, nem sempre de acordo com a atual jurisprudência do TCU.

O conhecimento tácito de servidores públicos, que não estava alinhado à jurisprudência do TCU, foi passível de responsabilização quando descobertos e evidenciados em auditoria; isso representa uma área de risco para os novos gestores universitários, porque está invisível na instituição pública pela falta de sistematização e estruturação formal.

Aspectos de gestão de pessoas também foram evidenciados em auditoria, principalmente a segregação de funções nas compras governamentais, justificada pela ausência de servidores públicos suficientes com formação para atuar nas 69 universidades federais como pregoeiros, fiscais de contrato, responsáveis pela pesquisa de preços e outras atividades de logística. A recomendação de compras conjuntas entre órgãos federais foi apontada em auditoria como uma maneira de diminuir a necessidade de replicar equipes de pregão para compras de material de consumo e bens permanentes de uso comum no governo federal.

Uma das limitações dessa pesquisa em Acórdãos do TCU é o foco em fraquezas na gestão pública, passíveis de responsabilização da autoridade competente. As entidades públicas de excelência não aparecem nas recomendações de auditoria, haja vista que o ciclo anterior da auditoria considerou satisfatório seu modus operandi, ou seja, seus atos administrativos estão de acordo com a legislação e a jurisprudência das EFS.

Por outro lado, essas fraquezas apontadas em auditoria revelam pontos a melhorar na gestão universitária, haja vista que outras entidades públicas já adotaram esses procedimentos administrativos, tendo excelência em compras governamentais e licitação.

\section{REFERÊNCIAS}

ABREU, R. M. de, MARRA, A. V. Mudança organizacional e as reações dos servidores após a implantação do REUNI. Revista GUAL, Florianópolis, v. 12, n. 3, p. 86-105, setembrodezembro 2019.

ALMEIDA, A. A. M. de, SANO, H. Função compras no setor público: desafios para o alcance da celeridade dos pregões eletrônicos. Revista de Administração Pública, v. 52, n. 1, p. 89-106, 2018. Doi: https://dx.doi.org/10.1590/0034-7612164213

ANDIFES. Associação Nacional dos Dirigentes das Instituições Federais de Ensino Superior. Painel de cortes em 2019. Disponível em: http://www.andifes.org.br/painel-dos-cortes. Acesso em: 31 maio 2020. 
ARANTES, R. B., ABRUCIO, F. L., TEIXEIRA, M. A. C. A imagem dos Tribunais de Contas subnacionais. Revista do Serviço Público, v. 56, n. 1, p. 57-83, 2005. Disponível em: https://bit.ly/2xHyF0s. Acesso em: 31 maio 2020.

BALLOU, R. H. Gerenciamento da cadeia de suprimentos: logística empresarial. 5. ed. Porto Alegre: Bookman, 2006.

BARDIN, L. Análise de conteúdo. 3. reimp. São Paulo: Edições 70, 2016.

BAUER, M. W., AARTS, B. A construção do corpus: um princípio para a coleta de dados qualitativos. In: Bauer, M. W.; Gaskell, G. (Orgs.). Pesquisa qualitativa com texto, imagem e som: um manual prático. 13. ed. Petrópolis. RJ: Vozes, 2015, p. 39-63.

BELL, F. Connectivism: its place in theory-informed research and innovation in technology enabled learning. The International Review of Research in Open and Distance Learning, v. 12 , n. 3, p. $98-118,2011$.

BEST, D. P. The future of information management. Records Management Journal, v. 20, n. 1, p. 61-71, 2010.

BOWERSOX, D. J. Gestão logística da cadeia de suprimentos. Porto Alegre: Bookman, 2006.

BRASIL. Controladoria-Geral da União. Manual de orientações técnicas da atividade de auditoria interna governamental do Poder Executivo Federal. Ministério da Transparência e Controladoria-Geral da União. Secretaria do Controle Interno. Brasília, DF: CGU, 2017a.

BRASIL. Ministério do Planejamento, Desenvolvimento e Gestão. Referencial de Governança e Gestão do Serviço de Serviços Gerais (SISG). Brasília: MP, 2017b.

BRASIL. Ministério do Planejamento, Orçamento e Gestão. Secretaria de Logística e Tecnologia da Informação. Estratégia Geral de Logística da Administração Pública Federal: EGL 2016/17. Brasília: MP, 2015.

CHOO, C. W. The knowing organization: how organizations use information to construct meaning, create knowledge and make decisions. 2. ed. New York: Oxford University Press, 2006.

CHOPRA, S., MEINDL, P. Gestão da cadeia de suprimentos: estratégia, planejamento e operação. 6. ed. São Paulo: Pearson Education do Brasil, 2016.

COOPER, D. R., SCHINDLER, P. S. Métodos de pesquisa em administração. 10. ed. Porto Alegre: Bookman, 2011.

COSTA, R. E., HOLLNAGEL, H. C., BUENO, R. L. P. Compras governamentais: panorama atual e desafios. Revista Científica Hermes, n. 23, p. 51-75, jan./abr. 2019. 
CRESWELL, J. W. Research design: qualitative, quantitative and mixed methods approaches. 2. Edition. Sage Publications, CA: Thousand Oaks, 2003.

CROTTY, M. The fundations of social research: meaning and perspective in the research process. London: Sage, 1998.

DAVENPORT, T. H. Ecologia da informação: por que só a tecnologia não basta para o sucesso na era da informação. São Paulo: Futura, 1998.

DE PAULA, A. P. P. Por uma nova gestão pública: limites e potencialidades da experiência contemporânea. Rio de Janeiro: Editora FGV, 2005.

DENHARDT, J. V., DENHARDT, R. B. The new public service: serving, not steering. New York: ME Sharpe, 2007.

DENHARDT, R. B., CATLAW, T. J. Teorias da administração pública. 7. ed. São Paulo: Cengage Learning, 2017.

DETLOR, B. Information management. International Journal of Information Management, v. 30, p. 103-108, 2010.

DIAS, L. dos P. P., GOMES, D. G. de, ANGONESE, R., QUINTANA, A. C. Auditoria interna e gestão: estudo de caso em uma universidade federal à luz da teoria institucional. Revista GUAL, Florianópolis, v. 13, n. 2, p. 116-139, maio-agosto 2020.

DUARTE, A. L. F., BOENTE, R. M. P., MARINHO, R. B. A., ZOUAIN, D. M. Produção acadêmica sobre 'accountability': categorizações na área de administração pública.

Contabilidade, Gestão e Governança, v. 21, n. 3, p. 459-475, 2018. Doi:

http://dx.doi.org/10.21714/1984-3925 2018v21n3a9

FLICK, U. Uma introdução à pesquisa qualitativa. 2. ed. Porto Alegre: Bookman, 2004.

GOEZ, W. L. C. Competência informacional na sociedade da informação: perspectivas e análise bibliométrica de modelos. Revista Brasileira de Biblioteconomia e Documentação, v. 14, n. 1, p. 109-125, 2018.

GONÇALVES, A. de O., SANTOS, R. L. A. dos, BILHIM, J. de A. F., COSTA, T. D. da. Que modelo é esse? As alterações nos processos de capacitação de recursos humanos nos 20 anos do Plano MARE. Administração Pública e Gestão Social, v. 9, p. 4, p. 298-309, 2017. Disponível em: https://periodicos.ufv.br/apgs/article/view/5129. Acesso em: 31 maio 2020.

ILLERIS, K. (Org.) Teorias contemporâneas da aprendizagem. Porto Alegre, RS: Penso, 2013.

INTOSAI. International Organization of Supreme Audit Institutions. Guidelines for the performance auditing process: ISSAI 3200/84. Viena, 2016. Disponível em:

https://bit.ly/3cnglIg. Acesso em: 31 maio 2020. 
JUSTEN FILHO, M. Comentários à lei de licitações e contratos administrativos. 9. ed. São Paulo: Dialética, 2002.

KELLE, U. Análise com auxílio de computador: codificação e indexação. In: Bauer, M. W.; Gaskell, G. (Orgs.). Pesquisa qualitativa com texto, imagem e som: Um manual prático. 13. ed. Petrópolis. RJ: Vozes, 2015, p. 393-415.

LARSON, P. D. Public vs. private sector perspectives on supply chain management. Journal of Public Procurement, v. 9, n. 2, p. 222-247, 2009.

LEITÃO, J. M., DANTAS, J. A. (2016). Materialidade em auditoria financeira no setor público: a prática internacional e a opinião de especialistas brasileiros. Contabilidade, Gestão e Governança, v. 19, n. 1, p. 146-166, 2016. Disponível em: https://bit.ly/2XQ6Iht. Acesso em: 31 maio 2020.

LIMA, S. L. L. de, GOMES, A. R. V., FERREIRA, R. M., WALTER, S. A. Mídias sociais, uma questão a ser enfrentada: a percepção dos alunos sobre as abordagens metodológicas e os princípios do conectivismo. Revista GUAL, Florianópolis, v. 13, n. 1, p. 115-136, janeiroabril 2020

LOURENÇO, R. P. An analysis of open government portals: a perspective of transparency for accountability. Government Information Quarterly, v. 32, n. 3, p. 323-332, 2015. Doi: https://doi.org/10.1016/j.giq.2015.05.006

MCCUE, C., PITZER, J. Fundamentals of leadership and management in public procurement. Herndon, VA: National Institute of Governmental Purchasing, 2005.

MCTIC. Ministério da Ciência, Tecnologia, Inovações e Comunicações (2020). Novo Marco Legal da Inovação: Código de Ciência, Tecnologia e Inovação, 2020. Disponível em: https://bit.ly/3aH3QX8. Acesso em: 31 de maio de 2020.

MELO FILHO, L. F. B. A licitação na Constituição de 1988. Disponível em: http://bit.ly/2spOF12. Acesso em: 31 maio 2020.

MONTEZANO, L., SILVA, N. B. da., MARQUES, F. B., ISIDRO-FILHO, A. Aspectos determinantes da implantação da gestão por competências em institutos federais. Revista GUAL, Florianópolis, v. 12, n. 3, p. 21-44, setembro-dezembro 2019.

MULGAN, G., ALBURY, D. Innovation in the public sector. London: Cabinet Office Strategy Unit, 2003.

OLIVEIRA, A. C., PINTO, F. R., MENDONÇA, C. M. C. de. Alinhamento estratégico de planejamentos institucionais: estudo em uma universidade federal da Amazônia Setentrional. Revista GUAL, Florianópolis, v. 13, n. 2, p. 183-205, maio-agosto 2020.

OPEN GOVERNMENT WORKING GROUP. Eigth principles of open government data, 2007. Disponível em: https://bit.ly/2VvrZvG. Acesso em: 31 maio 2020. 
ROMZEK, B. S., INGRAHAM, P. W. Cross pressures of accountability: initiative, command, and failure in the Ron Brown Plane Crash. Public Administration Review, v. 60, n. 3, p. 240-253, 2000. Doi: http://dx.doi.org/10.1111/0033-3352.00084

SÊMOLA, M. Gestão da segurança da informação: uma visão executiva. Rio de Janeiro: Campus, 2003.

SENGE, P. M. A quinta disciplina: arte e prática da organização que aprende. 27. ed. São Paulo: Best Seller, 2011.

SIEMENS, G. Conectivismo: uma teoria de aprendizagem para a idade digital, 2018.

Disponível em: http://bit.ly/2F4JBIg. Acesso em: 31 maio 2020.

SILVA, A. L. I. F., AZEVEDO, M. C., PINOCHET, L. H. C., OLIVEIRA, M. A. A influência da carreira proteana em suas respectivas âncoras na gestão de carreira de servidores públicos. Contabilidade, Gestão e Governança, v. 22, n. 1, p. 118-135, 2019. Disponível em: https://bit.ly/2xFPWHe. Acesso em: 31 maio 2020.

STN. Secretaria de Tesouro Nacional. Aspectos fiscais da educação no Brasil. Disponível em: http://bit.ly/2Md7QGW. Acesso em: 31 de maio de 2020.

TCU. Tribunal de Contas da União. Jurisprudência: Acórdãos (2020a). Disponível em: http://www.tcu.gov.br/. Acesso em: 31 maio 2020.

TCU. Tribunal de Contas da União. Controle e Fiscalização (2020b). Disponível em: https://bit.ly/352VVlU. Acesso em: 31 maio 2020.

TCU. Tribunal de Contas da União. Manual de auditoria operacional. 3. ed. Brasília: TCU, Secretaria de Fiscalização e Avaliação de Programas de Governo (Seprog), 2010.

TCU. Tribunal de Contas da União. Referencial básico do programa de inovação. Brasília: TCU, Instituto Serzedello Correa (ISC), Centro de Pesquisa e Inovação (CEPI), 2017.

Disponível em: https://bit.ly/2yNC8us. Acesso em: 31 maio 2020.

\section{NOTAS}

\footnotetext{
${ }^{\mathrm{i}}$ As atividade do pregoeiro estão previstas no artigo 11 do Decreto Federal n. 5.450/2005, a saber: a) coordenar o processo licitatório, b) receber, examinar e decidir as impugnações e consultas ao edital, apoiado pelo setor responsável pela sua elaboração, c) conduzir a sessão pública na internet, d) verificar a conformidade da proposta com os requisitos estabelecidos no instrumento convocatório, e) dirigir a etapa de lances, f) verificar e julgar as condições de habilitação, g) receber, examinar e decidir os recursos, encaminhando à autoridade competente quando mantiver sua decisão, h) indicar o vencedor do certame, i) adjudicar o objeto, quando não houver recurso, j) conduzir os trabalhos da equipe de apoio e k) encaminhar o processo devidamente instruído à autoridade superior e propor a homologação. Não há previsão desse cargo específico no rol de atividades das universidades federais brasileiras. São atividades complexas que precisam de capacitação contínua, bem como conhecimento da jurisprudência do TCU.

ii O sistema online Comprasnet, que é um sistema de E-Procurement, está disponível no Portal de Compras do Governo Federal em https://www.comprasgovernamentais.gov.br
} 